\title{
Emergency Peri-operative Management of Ruptured Humongous Lung Abscess: A combined effort makes the difference
}

\author{
Khalid Siddiqui ${ }^{1}$, Akbar Mistry ${ }^{1}$, and Muhammad Saad Yousuf ${ }^{1}$ \\ ${ }^{1}$ The Aga Khan University
}

December 28, 2021

\begin{abstract}
We are presenting a unique case, based on peri-operative management of a patient who was brought to the operating room for video-assisted thoracoscopy (VATS) for lung abscess decortication end up with right upper lobe of lung resection via thoracotomy in an emergency.
\end{abstract}

\section{INTRODUCTION}

Early thoracic empyema is usually treated through video-assisted thoracoscopic (VATS) decortication. However, in chronic empyema cases, it could be converted to thoracotomy in some cases. Careful patient selection is important for decortication if an effective surgical outcome is required. The preoperative workup should be thorough, and the surgery should be performed at a specific timed interval. ${ }^{1,2}$

Lung isolation techniques are required while providing anaesthesia for these patients. This is done to facilitate the surgeon while operating on the affected lung. Lung isolation has usually required in a condition of massive bleeding, pus, and bronchopleural fistula. The ultimate target is to protect the non-diseased contra-lateral lung from contamination. ${ }^{3}$

\section{CASE PRESENTATION}

A 20-year-old female was brought to the emergency room (ER) with signs of sepsis, hypotension, and multiorgan failure. She was a known case of insulin-dependent diabetes mellitus and was diagnoses with pulmonary tuberculosis 6 days prior to the day she presented to the ER. She had a history of productive cough, weight loss and fever for the last month. She was kept on anti-tuberculous medicines, but her condition deteriorated. Her CT scan was done which showed multiple cavitary lesions in the right lung (Figure 1). She was moved to the intensive care unit (ICU). Insulin infusion for the treatment of diabetic ketoacidosis was started in the ER. During her stay in the ICU, she developed hypoxia, acidosis and then a brief episode of pulseless ventricular tachycardia, then it was revived after performing ACLS protocol. She was intubated using a size $7 \mathrm{~mm}$ endotracheal tube and was shifted to the operating room for VATS and evacuation of the abscess.

She was brought to the operating room. Clinical monitoring was applied including ECG, End-tidal $\mathrm{CO}_{2}$ and pulse oximeter. Central venous pressure (CVP) in the right internal jugular vein and left radial artery cannulation of invasive blood pressure were also applied. The patient was connected to the anaesthesia machine and was kept on Isoflurane at a MAC between 0.8 and 1.0. $\mathrm{FiO}_{2}$ was kept between 0.5 and 1.0. Air was used to mix with oxygen and nitrous oxide was avoided. The patient was made left lateral for VATS and decortication. Infusion of cis-atracurium was started at $2 \mu \mathrm{gm} / \mathrm{kg} / \mathrm{min}$. For analgesia, morphine was given intravenously at $0.2 \mathrm{mg}$ per $\mathrm{kg}$. After the evacuation of the abscess, a major air leak was observed, and the patient started to develop hypoxia. We were unable to ventilate the patient with a ventilator, and oxygen saturation gradually dropped down to went down to $60 \%$ than jet ventilation was started using Sander's 
Manu jet Ventilator. After a modest increase in oxygenation, the patient started to desaturate again. On that occasion, surgeon found a large, ruptured lung abscess at the right upper lobe, which was destroyed, and the patient was an inability to ventilate due to a massive air leak from a ruptured abscess (Figure-2).

The surgeon immediately asked for lung isolation, we have inserted the 32 French left-sided double-lumen tube (DLT) via the help of a video laryngoscope without turning to the patient on a supine position. The tracheal lumen was immediately clamped, and the left lung was ventilated differentially. After recruitment maneuver at a pressure of $30 \mathrm{~cm} \mathrm{H}_{2} \mathrm{O}$, the oxygen saturation rose to $92 \%$ after which it was decided to go for right upper lobe lobectomy. During the surgery, one packed red blood cell was transfused. For hypotension, boluses of phenylephrine 100ugm were given. After lobectomy, the wound was closed, and a chest drain was kept in place. The double-lumen endotracheal tube was replaced with a single lumen PVC tube size $7 \mathrm{~mm}$ using a video laryngoscope before shifting the patient to the ICU in stable condition.

\section{DISCUSSION}

Lung abscesses are uncommon, but they have a high fatality rate. Normally, they can be addressed without the need for surgery. Required, surgery can result in soiling or a significant bronchopleural fistula. Patients with sepsis secondary to long-standing lung abscess pose a challenge to both surgeons and anaesthetists when they are brought to the operating room for evacuation of abscess as they frequently necessitate onelung ventilation. Not only ventilation is challenging, but the overall management of the patient with respect to the management of airway, maintaining oxygenation, and switching to an alternative airway in case of a change in surgical plan can all be part and parcel while giving anaesthesia.

Thoracic surgeries often require modified ventilation either to facilitate the surgeon or to protect the healthy lung to get contaminated from the infected lung. Bronchopleural fistula or a single-sided damage to the airway or lung often causes difficulty in ventilation while using positive pressure. Lung isolation, where possible and indicated, can be performed using double-lumen tubes, bronchial blockers, or selectively intubating one lung using a fiberoptic technique. ${ }^{4}$

Surgical care of a lung abscess has become more complicated in recent years, as neither the timing nor the indication for a related surgical surgery is well established. Numerous factors complicate surgical care and outcomes, with existing comorbid, severity of lung injury, and type of interventions. Surgery indicated in refractory to medical therapy, life-threatening hemoptysis, cavitary lesion more than $6 \mathrm{~cm}$ in diameter, bronchopleural fistula, and ruptured abscess pleural cavity with pleural empyema. ${ }^{5}$

The purpose of surgical handling for localized infection is to eradicate necrotic lung abscess debris that could serve as a reservoir for recurrent infection. ${ }^{6}$ Lobectomy is usually proposed for a large cavity of lung abscess. ${ }^{7}$ Atypical pulmonary resection or segmentectomy is enough if it could eradicate the affected lesions of abscess completely. ${ }^{8}$

The main aim of anaesthetic part is to protect the healthy parts of the lung from the abscess. The regular suctioning of the secretions during surgery via the DLT lumen on the diseased side is the standard recommendation. Furthermore, until the risk of contamination is eliminated, avoid ventilation of lung with abscess. Management of airway must be tailored according to the patients' requirement and oxygenation should always be the main priority in every form of surgery. ${ }^{9}$

In this case, the situation was rapidly changed when lung abscess was ruptured and immediate measures to lung isolation and surgical resection was done without any dilemma. Lobectomy can only be done once the lung was completely isolated and maintaining perfusion and ventilation of the relatively healthy lung help in managing hypoxia.

\section{CONCLUSION}

Successful team effort with both surgical and anaesthetic, with timely lung isolation and resection of lung or lobe than a successful outcome resulted. Peri-operative management including pre-op evaluation, intraoperative anesthetic management, and postoperative analgesia are vital fundamentals to consider in guaranteeing 
the best outcome for the patient.

ACKNOWLEDGEMENT The authors would like to thank all of those people who contributed to prepare this report especially Ms Asma Faraz (Research Associate) Department of Anaesthesiology, Aga Khan University.

\section{CONFLICT OF INTEREST}

The authors have no conflict of interest to declare.

\section{AUTHOR CONTRIBUTION}

KMS conceptualized, wrote the original draft and reviewed the final manuscript; SY, and AA participated in literature review and edited the manuscript; AA taken the photograph, SY; revised and edited the manuscript.

\section{CONSENT}

Published with written consent of the patient.

\section{DATA AVAILABILITY STATEMENT}

The data that support the findings of this study are available from the corresponding author upon reasonable request.

\section{FIGURE LEGENDS:}

Figure 1: CT scan of the patient showing multiple cavitation and right-sided empyema

Figure2: Resected part of the ruptured right upper lobe of lung abscess

\section{REFERENCES}

1. Lambright ES. Decortication and pleurectomy. Souba WW, Fink MP, Jurkovich GJ, et al, eds. ACS Surgery: Principles and Practice. 6th ed. New York: WebMD; 2007. 448-53.

2. Subotic D, Lardinois D, Hojski A. Minimally invasive thoracic surgery for empyema. Breathe (Sheff). 2018;14 (4):302-310. doi:10.1183/20734735.025718.

3. Slinger PD, Campos JH. Anesthesia for Thoracic Surgery, Chapter. 53. In: Miller's Anesthesia. 9th ed. 2020. p. 1648-1716.

4. Loop T, Spaeth J. Atemwegsmanagement in der Thoraxanästhesie mit dem Doppellumentubus [Airway Management in Thoracic Anesthesia with Double-Lumen Tube]. Anasthesiol Intensivmed Notfallmed Schmerzther. 2018;53 (3):174-185. doi:10.1055/s-0043-114678.

5. Schweigert M, Solymosi N, Dubecz A, et al. Predictors of Outcome in Modern Surgery for Lung Abscess. Thorac Cardiovasc Surg.2017;65 (7):535-541. doi:10.1055/s-0037-1598113.

6. Schuchert MJ, Pettiford BL, Keeley S, et al. Anatomic segmentectomy in the treatment of stage I nonsmall cell lung cancer. Ann Thorac Surg. 2007;84 (3):926-933. doi:10.1016/j.athoracsur.2007.05.007.

7. Refaely Y, Weissberg D. Gangrene of the lung: treatment in two stages.Ann Thorac Surg. 1997;64 (4):970-974. doi:10.1016/s0003-4975(97)00837-0.

8. Sun Y, Hou L, Xie H, et al. Wedge resection for localized infectious lesions: high margin/lesion ratio guaranteed operational safety. J Thorac Dis. 2014;6 (9):1173-1179. doi:10.3978/j.issn.2072-1439.2014.08.30.

9. Ochroch, Andrew E. MD Thoracic Anesthesia, Anesthesia \& Analgesia: November 2003 - Volume 97 Issue 5 - p 155. 

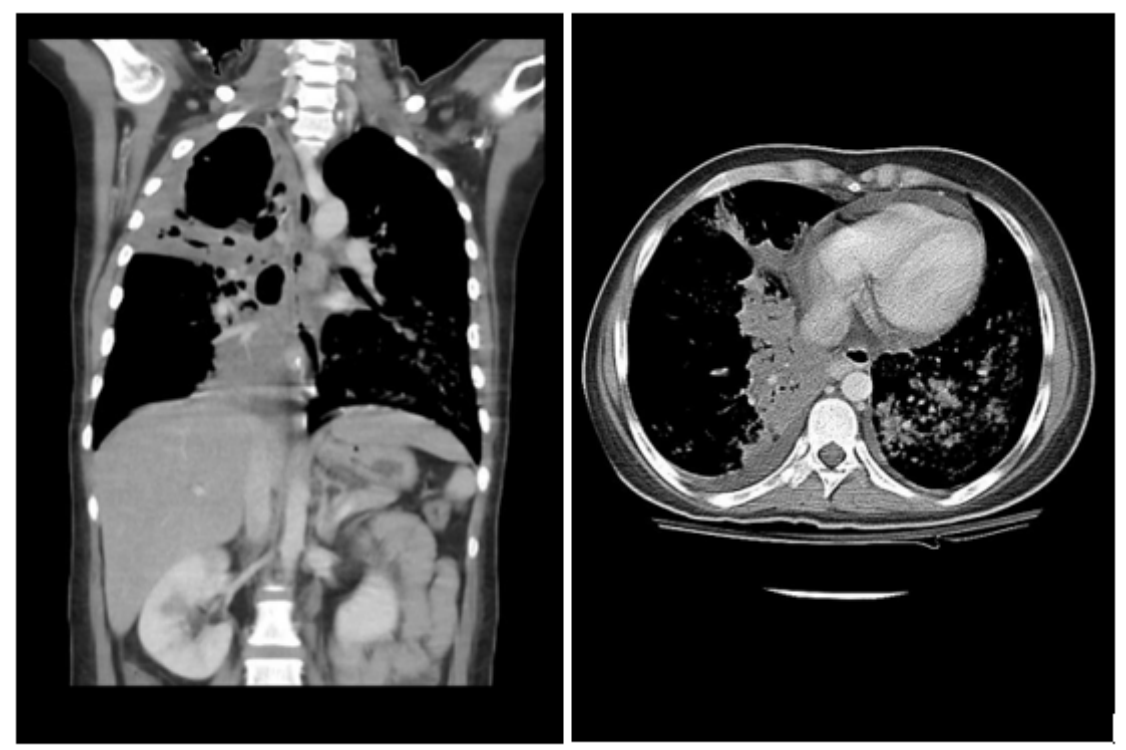


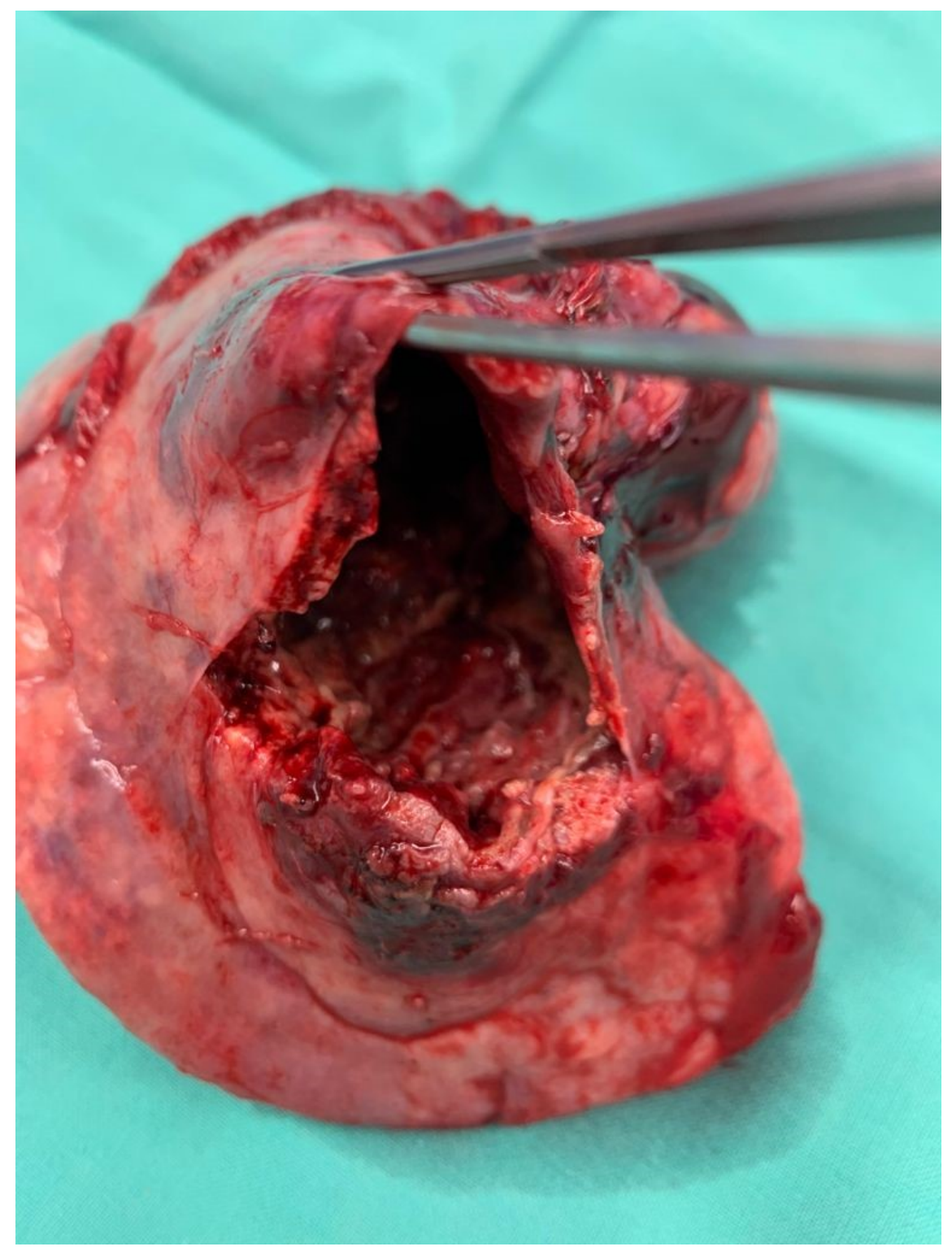

